\title{
Solution properties and comparative antimicrobial efficacy study of different brands of toothpaste of Nepal
}

\author{
Narendra Kumar Chaudhary ${ }^{1 *}$, Biswash Guragain ${ }^{1}$, Reena Lamichhane-Khadka² and Ajaya Bhattarai ${ }^{1}$
}

\begin{abstract}
Background: The main objective of this study is to compare the effectiveness of toothpaste formulations in giving total protection to the oral cavity. So, three important solution properties: surface tension, conductivity, and pH measurements, have been investigated for eight kinds of commercial herbal and non-herbal based toothpaste of Nepal. The study was extended to evaluate the antibacterial efficacy of toothpaste formulations against the Grampositive bacteria Staphylococcus aureus (S. aureus) and Gram-negative bacteria Escherichia coli (E. coli), and this was done by standard agar well diffusion technique. Amikacin (30 $\mathrm{\mu g} /$ disk) was used as a positive control to compare the antibacterial potency of the investigated toothpaste.

Results: The surface tension of all toothpaste formulations increased with the decrease in concentration. However, the conductivity of the formulations decreased with the decrease in concentration. The highest pH of 8.24 was recorded for Dabur Super Salt (DSS) and all values were found to be higher in tap water solutions. All toothpaste formulations showed significant growth inhibition against both S. aureus and E. coli. The overall antibacterial sensitivity of Dabur Red (DR) is higher for S. aureus. The solid material content was found to be highest for Dabur Herbal Gel (DHG) and lowest for Pepsodent (PD).

Conclusion: The findings of the present study showed all toothpaste formulations as effective in inhibiting the growth of tested bacterial species. Toothpaste formulations were found slightly alkaline, which favors bacterial growth inhibition. Increasing surface tension and decreasing conductivity value of toothpaste relative to a decrease in concentration favor its desirable cleansing action.
\end{abstract}

Keywords: Toothpaste, Oral disease, Antibacterial evaluation, Conductivity, Surface tension

\section{Background}

Organic biofilm formation in the oral cavity is the main cause of microfloral growth. Not taking proper care can lead to several oral diseases, including tooth decay. So, the current dental research is attracting the active knowledge of pharmacists to design and develop various chemical and herbal-based toothpaste formulations for the better cure and to strengthen the teeth of people.

\footnotetext{
* Correspondence: chem_narendra@yahoo.com

'Department of Chemistry, Mahendra Morang Adarsh Multiple Campus, (Tribhuvan University), Biratnagar 56613, Nepal

Full list of author information is available at the end of the article
}

The most common problems in the oral environment are dental caries and plaque $[1,2]$. The dental problems have become a significant health problem in the leastdeveloped countries like Nepal, where the majority of the people are illiterate. Gingivitis is another oral disease whose prevalence increases with the age of the people. Mostly, the post-aged people are more vulnerable to plaque-induced gingivitis [3]. These diseases are caused by oral biofilm formation, which generates a suitable medium for the growth of many microbiota. Some strains of $S$. aureus have been reported in the oral cavity that is associated with oral infections like angular cheilitis, parotitis, and staphylococcal mucositis $[4,5]$.

\section{Springer Open}

(c) The Author(s). 2020 Open Access This article is licensed under a Creative Commons Attribution 4.0 International License, which permits use, sharing, adaptation, distribution and reproduction in any medium or format, as long as you give appropriate credit to the original author(s) and the source, provide a link to the Creative Commons licence, and indicate if changes were made. The images or other third party material in this article are included in the article's Creative Commons licence, unless indicated otherwise in a credit line to the material. If material is not included in the article's Creative Commons licence and your intended use is not permitted by statutory regulation or exceeds the permitted use, you will need to obtain permission directly from the copyright holder. To view a copy of this licence, visit http://creativecommons.org/licenses/by/4.0/. 
Similarly, E. coli strains are also reported to cause bilateral maxillary necrosis [6]. Therefore, proper attention to oral hygiene seems very important. Daily brushing with toothpaste and washing of the oral cavity are the only strategies to overcome these diseases $[7,8]$. The rural Nepalese people have the common practice of dental caring by mechanical brushing with bamboo stems and other plant parts. However, in recent years, this system of brushing has been changed, and people use a toothbrush with different types of toothpaste formulations for dental caring. Despite the mechanical brushing approach for removal of oral biofilm, chemical formulations are also available, to enhance the efficacy of brushing and thereby prevent diseases. Various types of toothpaste and mouth rinse formulations with antimicrobial properties have been developed to fight oral microbial in the mouth cavity $[9,10]$. Toothpaste generally contains abrasives, surfactants, anticaries agents, copolymers, pH buffers, humectants, and binders. Different kinds of toothpaste contain different ingredients in various quantities. Even though all toothpaste lowers the surface tension of liquids, the extent is no longer equal, and so, there would be variation in their cleansing action [11, 12].

Toothpaste is used to promote oral hygiene and deliver active ingredients to protect the teeth from dental caries and gum diseases. The chemical-based toothpaste possesses active ingredients like fluoride, surfactant (detergents), antimicrobials, and bleaching agents for the whitening of teeth. Besides the dental caring effects, these chemicals may pose a risk factor if swallowed in large amounts and sometimes becomes acute also [13]. The pure herbal-based toothpaste is not much effective in performing all the activities for maintaining oral hygiene; instead, they are less toxic. Moreover, their effectiveness has been ameliorated by the combined effect of several plant extracts. Most of the herbal-based toothpaste possesses clove oil and mentha species to amplify antimicrobial property. For example, Neem leaf extract has a natural antibacterial property and gives complete natural oral hygiene $[14,15]$. Recently, the combination of chemical and herbal-based toothpaste is also available in the market to promote dental care and to reduce the toxic effects caused by chemical agents. Besides the antimicrobial activity, several physical properties of the toothpaste, such as surface tension, conductivity, and $\mathrm{pH}$ may play a significant role in the removal of oral biofilm and enhance cleansing action [16].

The surface tension is an essential solution parameter of surfactant-based toothpaste. Toothpaste reduces surface tension and promotes better cleansing action [17]. Their conductivity depends upon the nature of ions formed after ionization, nature of the solvent used, temperature, and presence of additives like salts [18]. Van Asselt et al. illustrated that conductivity could be used to monitor the cleansing and to distinguish between the different cleansing phases [19]. The alkaline nature of toothpaste has a significant advantage in neutralizing acids produced by bacterial action on food particles and prevents tooth decay. Alkaline toothpaste causes less spoilage of the dental surface, whereas acidic toothpaste with lower $\mathrm{pH}$ has shown more significant transformation effects [20]. Eventually, the $\mathrm{pH}$ of toothpaste is essential to maintain the alkaline medium of the oral cavity, which inhibits bacterial growth in the oral environment [16]. The literature suggests $\mathrm{pH}$ as an important property of toothpaste for effects on the enamel surface [21].

The present research work aims to evaluate the physical and solution properties of eight dentifrice formulations containing both herbal and chemical ingredients. These were screened for in vitro antibacterial efficacy to compare their effectiveness towards tooth decaying bacteria [9, 22]. Most of the plant extracts added to the herbal-based toothpaste possess medicinal values. So, the antibacterial efficacies of such herbal and chemicalbased toothpaste were compared and evaluated.

\section{Materials and methods}

\subsection{Materials and instruments}

All the chemicals and reagents used in this experiment were of analytical reagent grade. Amikacin disk, Nutrient Broth (NB), Nutrient Agar (NA), and Mueller Hinton's Agar (MHA) were obtained from Hi-Media Laboratories, Pvt. Ltd. Mumbai, India. Eight kinds of toothpaste were selected and purchased from the local market of Biratnagar, Nepal. These dentifrice formulations are coded as Dabur Red (DR), Pepsodent (PD), Srikhanda Herbal (SKH), Dabur Herbal (DH), Aagaman Neem Herbal (ANH), Dabur Herbal Gel (DHG), Dabur Super Salt (DSS), and Close Up (CU). Their ingredients are listed in Table S1. These are grouped into three types: pure chemical-based, pure herbal-based, and the combination of both herbal and chemical-based toothpaste. The dentifrice DR is an herbal-based toothpaste with chemical preservatives. The toothpaste $\mathrm{SKH}$ and $\mathrm{ANH}$ contain fluoride along with herbal constituents. DH, DHG, and DSS contain both herbal and chemical constituents. PD contains fluoride, chemicals, and herbal components, and $\mathrm{CU}$ is pure chemical-based dentifrice. The surface tension was measured by Force Tensiometer-K20, using a platinum ring by the ring detachment technique. The auto-ranging digital Conductivity/TDS meter, TCM 15+ was employed to measure the electrical conductance of the toothpaste solutions. The $\mathrm{pH}$ of the solutions was measured by the Eutech ${ }^{\mathrm{TM}}$ Ion $2700 \mathrm{pH}$ meter. 


\subsection{Methods}

The glasswares were washed with triple-distilled water before use and dried in the oven. For the solution properties study, the solution of toothpaste was made in sterile pyrogen-free distilled water and normal tap water. All solutions were centrifuged for half an hour and the clear liquid so obtained was used for the solution properties study. Six different concentrations of toothpaste solution in water at a ratio 1:50, 1:100, 1: $200,1: 400,1: 800$, and 1:1600 were obtained using the internal dilutions technique. The surface tension, conductivity, and $\mathrm{pH}$ were then simultaneously measured.

The antibacterial property of the toothpaste formulations was tested in vitro against the Gram-positive bacteria $S$. aureus, and the Gram-negative bacteria $E$. coli using the standard agar well diffusion method [23]. The specific isolates of $S$. aureus (ATCC 25923) and E. coli (ATCC 25922) were cultured and stored in Mueller Hinton's Agar (MHA) plates at $4{ }^{\circ} \mathrm{C}$ until their use. For each toothpaste formulation, four different concentrations were tested against each bacterial species (Table 4). Bacterial cultures were revived by seeding a few colonies from a fresh plate culture into $5 \mathrm{ml}$ nutrient broth and allowing incubation at room temperature for $2 \mathrm{~h}$. The bacterial cultures were then streaked uniformly onto the surface of sterile MHA plates. Wells of 5-mm diameter were punched off on the inoculated MHA plates using a sterile $5-\mathrm{mm}$ cork-borer. The wells were loaded with $50 \mu \mathrm{L}$ of the toothpaste solutions [23-25]. An amikacin disk $(30 \mu \mathrm{g})$ was placed on each agar plate. After incubating the plates at $37{ }^{\circ} \mathrm{C}$ for $24 \mathrm{~h}$, the diameters of the zone of inhibition were measured and compared. The entire experiment was repeated three times to reduce error, and the measurements of the zone of inhibition for $S$. aureus and $E$. coli were compared using the Student's two-tailed $t$ test $(P<0.01$ and $P<0.005)$ $[26,27]$.

\section{Results}

\subsection{Solution properties}

The surface tension data of all the toothpaste formulations at their six different concentrations in DW and TW at room temperature are presented in Table 1 and Figures S1 and S2. At all their concentrations, the order of surface tension was DSS $>$ DR $>$ DH $>$ DHG $>$ ANH $>\mathrm{SKH}>\mathrm{PD}>\mathrm{CU}$ in DW as well as in TW solution. The specific conductivity of toothpaste samples was measured at room temperature in both DW and TW, and the data are presented in Table 2 and Figures S3 and S4. The data revealed a low specific conductivity value of toothpaste in DW relative to TW at all concentrations. The graphical pattern was almost similar in both cases, and there was a decrease in specific conductivity with dilution for all toothpaste. The variation of specific conductivity with toothpaste concentration was found linear. We, therefore, determined the intercept and slopes from the linear variation of the conductivity data with the correlation coefficient, which was found higher than 0.99 (Figures S5 and S6). The $\mathrm{pH}$ data of all the investigated toothpaste in aqueous solutions are reported in Table 3. The graphical information of the change in $\mathrm{pH}$ with concentration is illustrated in Figures $\mathrm{S} 7$ and S8. In general, $\mathrm{pH}$ decreased with increasing dilution of toothpaste solutions.

\subsection{Percentage solid content}

The percentage solid content of various types of toothpaste gives an idea about the amount of dry matter present in it that would participate in cleansing and protective action. Of the eight types of toothpaste selected for the study, DHG has the highest (78.77\%) while PD has the lowest (63.94\%) content of the embedded materials. Others occupy an intermediate position with the range (69.27-76.29) percent, not too far from the highest value (Fig. 1).

Table 1 Surface tension of toothpaste samples in distilled water (DW) and Tap water (TW) at room temperature

\begin{tabular}{|c|c|c|c|c|c|c|c|c|c|c|c|c|}
\hline \multirow{3}{*}{ Toothpaste } & \multicolumn{12}{|c|}{ Surface tension $(\mathrm{mN} / \mathrm{m})$} \\
\hline & \multicolumn{2}{|l|}{$1: 50$} & \multicolumn{2}{|c|}{$1: 100$} & \multicolumn{2}{|l|}{$1: 200$} & \multicolumn{2}{|l|}{$1: 400$} & \multicolumn{2}{|l|}{$1: 800$} & \multicolumn{2}{|c|}{$1: 1600$} \\
\hline & DW & TW & DW & TW & DW & TW & DW & TW & DW & TW & DW & TW \\
\hline $\mathrm{DR}(2)$ & 34.3 & 32.1 & 46.0 & 38.0 & 58.9 & 46.8 & 65 & 55.1 & 68.5 & 62.8 & 71.0 & 68.1 \\
\hline $\mathrm{PD}(7)$ & 27 & 25.5 & 29.6 & 28.1 & 39.7 & 33.4 & 50.5 & 39.2 & 62.5 & 44.4 & 68.3 & 58.0 \\
\hline SKH (6) & 30.6 & 27.6 & 38 & 34.7 & 49.5 & 41.7 & 59.6 & 45.7 & 66.0 & 54.1 & 69.1 & 66.2 \\
\hline $\mathrm{DH}(3)$ & 34 & 30.6 & 44.3 & 37.0 & 55.6 & 46.2 & 64.0 & 54.3 & 68 & 62.4 & 70 & 68.0 \\
\hline ANH (5) & 31.5 & 28.1 & 39.0 & 35.5 & 51.4 & 42.4 & 60.9 & 46.0 & 67.2 & 54.6 & 69.3 & 66.5 \\
\hline $\mathrm{DHG}(4)$ & 32.8 & 29.1 & 42 & 36.1 & 53 & 43.1 & 61 & 46.9 & 67.5 & 55.4 & 69.5 & 67.1 \\
\hline DSS (1) & 35.9 & 34.6 & 48 & 39.1 & 60.9 & 49.0 & 66 & 56.3 & 69.5 & 63.0 & 71.2 & 68.2 \\
\hline CU (8) & 24.6 & 24.4 & 24.7 & 25.0 & 26.0 & 25.2 & 29.5 & 27.6 & 40.9 & 35.8 & 59.7 & 56.6 \\
\hline
\end{tabular}


Table 2 Specific conductivity of toothpaste samples in distilled water (DW) and tap water (TW) at room temperature

\begin{tabular}{|c|c|c|c|c|c|c|c|c|c|c|c|c|}
\hline \multirow[t]{3}{*}{ Toothpaste } & \multicolumn{12}{|c|}{ Specific conductivity ( $\mu$ Siemen/cm) } \\
\hline & \multicolumn{2}{|l|}{$1: 50$} & \multicolumn{2}{|c|}{$1: 100$} & \multicolumn{2}{|c|}{$1: 200$} & \multicolumn{2}{|c|}{$1: 400$} & \multicolumn{2}{|c|}{$1: 800$} & \multicolumn{2}{|c|}{$1: 1600$} \\
\hline & DW & TW & DW & TW & DW & TW & DW & TW & DW & TW & DW & TW \\
\hline DR & 318 & 550 & 166 & 427 & 91 & 365 & 50 & 330 & 24 & 305 & 7 & 292 \\
\hline PD & 507 & 779 & 255 & 541 & 125 & 428 & 61 & 370 & 29 & 334 & 10 & 319 \\
\hline SKH & 245 & 506 & 125 & 401 & 60 & 342 & 25 & 305 & 13 & 284 & 3 & 277 \\
\hline $\mathrm{DH}$ & 295 & 529 & 147 & 421 & 70 & 353 & 32 & 315 & 16 & 293 & 5 & 280 \\
\hline $\mathrm{ANH}$ & 268 & 519 & 139 & 418 & 64 & 348 & 28 & 310 & 15 & 288 & 4 & 278 \\
\hline DHG & 298 & 543 & 155 & 424 & 73 & 357 & 38 & 320 & 17 & 295 & 6 & 284 \\
\hline DSS & 666 & 918 & 345 & 629 & 172 & 477 & 82 & 398 & 35 & 361 & 12 & 342 \\
\hline CU & 473 & 665 & 221 & 491 & 112 & 399 & 52 & 350 & 26 & 322 & 9 & 305 \\
\hline
\end{tabular}

\subsection{Antibacterial sensitivity study}

In vitro antibacterial evaluation of toothpaste formulations were conducted to assess their growth inhibitory activity against two common representative species of Gram-positive and Gram-negative bacteria, S. aureus and $E$. coli, respectively. The toothpaste formulations produced larger zones of inhibition for $S$. aureus than $E$. coli (Table 4, Figs. 2 and 3). The bacterial growth inhibition was found to be higher and more consistent at higher concentrations of the formulations. Compared to different brands of toothpaste, ANH displayed considerably higher inhibition for both $S$. aureus and E. coli at all four tested concentrations. Comparatively high inhibitory patterns were exhibited by all four concentrations of SKH. Interestingly, toothpaste DR showed the highest antibacterial potency against $S$. aureus at 1:1 concentration, but the weakest inhibition at concentrations 1:4 and 1:8. A similar pattern was seen for this toothpaste with E. coli as well.

The analysis of the results of the antimicrobial susceptibility test was based on the comparison of the zones of inhibition formed by the toothpaste formulations, possibly due to the active antimicrobial agents present in the toothpaste. The amikacin disk $(30 \mu \mathrm{g} /$ disk $)$ was included in the test as a reference for the comparison of growth inhibitors by toothpaste. Amikacin is a broadspectrum aminoglycoside antibiotic widely used in the treatment of infections with Gram-positive and Gramnegative bacteria, including otherwise aminoglycosideresistant bacteria [28, 29]. Size of the zones of inhibition produced by the highest concentrations of toothpaste formulations for both $S$. aureus and E. coli was comparable to that formed by the amikacin disks, indicating that both species are sensitive to the highest concentration of the toothpaste formulations. Overall, all eight kinds of toothpaste formulations demonstrated a high inhibitory effect against $S$. aureus. E. coli was only resistant to PD at 1:8 concentrations. In general, herbal-based toothpaste has better inhibitory activity than non-herbal toothpaste.

\section{Discussion}

Our report on the study of the solution properties of toothpaste can be a benchmark for evaluating their effectiveness towards cleansing action. All investigated

Table $3 \mathrm{pH}$ of toothpaste samples in distilled water (DW) and Tap water (TW) at room temperature

\begin{tabular}{|c|c|c|c|c|c|c|c|c|c|c|c|c|}
\hline \multirow[t]{3}{*}{ Toothpaste } & \multicolumn{12}{|l|}{$\mathrm{pH}$} \\
\hline & \multicolumn{2}{|l|}{$1: 50$} & \multicolumn{2}{|l|}{$1: 100$} & \multicolumn{2}{|l|}{$1: 200$} & \multicolumn{2}{|l|}{$1: 400$} & \multicolumn{2}{|l|}{$1: 800$} & \multicolumn{2}{|c|}{$1: 1600$} \\
\hline & DW & TW & DW & TW & DW & TW & DW & TW & DW & TW & DW & TW \\
\hline DR & 7.45 & 7.64 & 7.21 & 7.25 & 6.84 & 6.88 & 6.63 & 6.68 & 6.43 & 6.47 & 6.33 & 6.35 \\
\hline PD & 7.13 & 7.50 & 7.08 & 7.09 & 6.80 & 6.82 & 6.50 & 6.54 & 6.31 & 6.36 & 6.22 & 6.23 \\
\hline SKH & 7.15 & 7.53 & 7.10 & 7.23 & 6.82 & 6.86 & 6.52 & 6.56 & 6.33 & 6.37 & 6.23 & 6.24 \\
\hline $\mathrm{DH}$ & 7.49 & 7.75 & 7.23 & 7.44 & 6.90 & 7.15 & 6.70 & 6.89 & 6.61 & 6.70 & 6.45 & 6.54 \\
\hline $\mathrm{ANH}$ & 6.86 & 6.87 & 6.84 & 6.85 & 6.66 & 6.73 & 6.48 & 6.52 & 6.24 & 6.35 & 6.11 & 6.22 \\
\hline $\mathrm{DHG}$ & 6.83 & 6.85 & 6.81 & 6.84 & 6.62 & 6.72 & 6.45 & 6.50 & 6.18 & 6.30 & 6.07 & 6.19 \\
\hline DSS & 8.20 & 8.24 & 8.17 & 8.22 & 7.94 & 8.03 & 7.64 & 7.65 & 7.13 & 7.15 & 6.80 & 6.83 \\
\hline $\mathrm{CU}$ & 6.60 & 6.65 & 6.56 & 6.60 & 6.43 & 6.57 & 6.29 & 6.46 & 6.14 & 6.25 & 6.03 & 6.15 \\
\hline
\end{tabular}




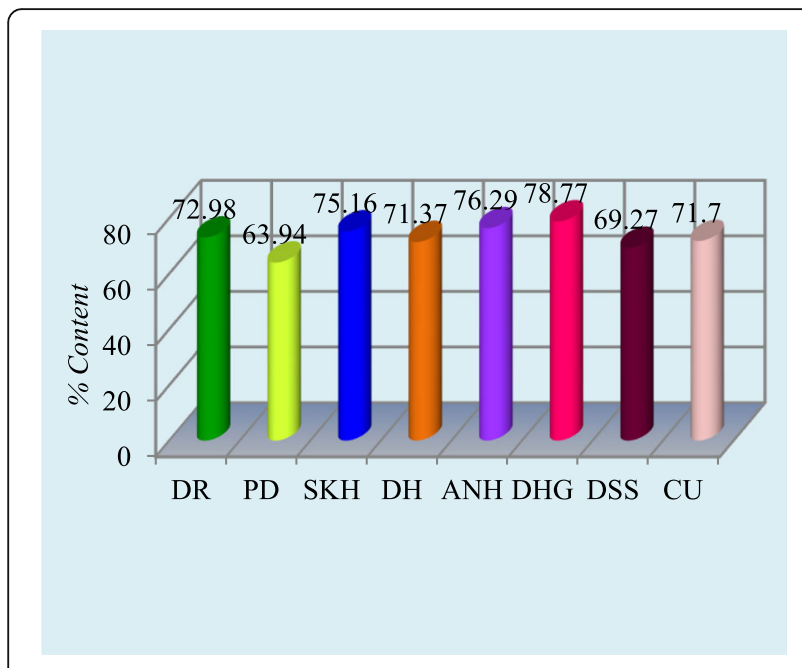

Fig. 1 Percentage solid content of toothpastes after 1 month drying

toothpaste showed higher surface tension values in distilled water than tap water. The decrease in surface tension is proportional to the adsorbed amount of surfactant, as shown by the Gibbs adsorption isotherm. As we know, tap water contains salts whereas distilled water does not contain any salts. Adding salt reduces electrostatic repulsion between ionized head groups of surfactants, so they can pack together at the interface. Therefore, more surfactant is adsorbed and causes more reduction of surface tension [30]. Our data of high surface tension of all investigated toothpaste in distilled water and low surface tension in tap water also coincide with most investigated toothpaste in the literature [31].

At their lowest experimental concentration, toothpaste solutions have been found with relatively high surface tension values and reverse with high concentration. The results showed an increasing trend of surface tension upon dilution of the toothpaste solution. This may also be due to the increase of the water portion and the formation of monolayer and ionic micelles at low concentrations $[17,31]$. Such variations regarding high and low concentrations of toothpaste at surface tension were also found by Gordon and Shand [31]. It was claimed by Gordon and Shand that the effectiveness of toothpaste is mainly due to friction between teeth and brushes, and the support of other substances involved is of negligible importance [31]. Even a toothpaste with the lowest surface tension value cannot remove all the particles of debris that have been lodged between the cervices only. Hattiangdi et al. concluded that soapless detergents are better than surface cleaning agents due to their low surface tension values compared to soaps with low concentrations [17].

Despite the differences, both soap and toothpaste have surfactants aimed at reducing surface tension and require friction for cleaning. And yet, without them, no better cleanup is achieved. Surface tension studies should, therefore, be of importance in the cleaning action. Some studies of surface tension on toothpaste prove that low surface tension helps in better teeth cleaning [32]. Lower surface tension is possible only in an aqueous medium that combines with toothpaste containing the surfactant.

The specific conductivity of toothpaste in distilled water was found to be lower than that in tap water, and this is probably due to the presence of ionic impurities in tap water which increases the mobility of ions. All investigated toothpaste has a specific conductivity reduction with dilution. The decrease in conductivity, along with dilution, is due to the replacement of ions by the colloidal particles, which, when conducting, have lower conductivity than the ions from which they are formed. Colloidal particles are thus formed in very low

Table 4 Antibacterial sensitivity of S. aureus and E. coli with tested toothpastes

\begin{tabular}{|c|c|c|c|c|c|c|c|c|}
\hline \multirow[t]{3}{*}{ Toothpastes } & \multicolumn{8}{|c|}{ The diameter of the zone of inhibition in $\mathrm{mm}$} \\
\hline & \multicolumn{4}{|l|}{ S. aureus } & \multicolumn{4}{|l|}{ E. coli } \\
\hline & $1: 1$ & $1: 2$ & $1: 4$ & $1: 8$ & $1: 1$ & $1: 2$ & $1: 4$ & $1: 8$ \\
\hline$\overline{D R}$ & $23.0 \pm 1.0^{* *}$ & $17.7 \pm 0.6^{*}$ & $12.3 \pm 2.1$ & $7.3 \pm 0.6$ & $15.3 \pm 0.6$ & $15.3 \pm 0.6$ & $8.0 \pm 1.0$ & $7.7 \pm 0.6$ \\
\hline PD & $18.7 \pm 0.6$ & $17.0 \pm 1.0$ & $15.3 \pm 0.6^{* *}$ & $14.0 \pm 1.0^{* *}$ & $17.0 \pm 1.0$ & $14.0 \pm 1.0$ & $12.7 \pm 0.6$ & $6.7 \pm 0.6$ \\
\hline $\mathrm{SKH}$ & $20.0 \pm 1.0^{*}$ & $17.3 \pm 1.2$ & $15.7 \pm 0.6$ & $12.0 \pm 1.0$ & $15.7 \pm 1.2$ & $15.7 \pm 1.2$ & $12.7 \pm 1.2$ & $10.0 \pm 1.0$ \\
\hline $\mathrm{DH}$ & $19.7 \pm 1.2^{* *}$ & $18.3 \pm 0.6^{* *}$ & $16.7 \pm 0.6^{* *}$ & $11.0 \pm 1.0^{*}$ & $14.7 \pm 0.6$ & $12.7 \pm 0.6$ & $10.3 \pm 0.6$ & $7.7 \pm 0.6$ \\
\hline ANH & $21.3 \pm 0.6^{* *}$ & $20.0 \pm 1.0^{*}$ & $20.3 \pm 0.6^{* *}$ & $12.7 \pm 0.6$ & $16.0 \pm 1.0$ & $14.7 \pm 0.6$ & $14.0 \pm 1.0$ & $12.3 \pm 0.6$ \\
\hline DHG & $19.0 \pm 1.0^{* *}$ & $18.0 \pm 1.0^{* *}$ & $18.3 \pm 0.6^{* *}$ & $10.0 \pm 1.0$ & $13.7 \pm 0.6$ & $13.3 \pm 0.6$ & $12.7 \pm 0.6$ & $12.0 \pm 1.0$ \\
\hline DSS & $19.7 \pm 1.5$ & $16.0 \pm 1.0^{*}$ & $15.0 \pm 1.0^{* *}$ & $10.3 \pm 0.6$ & $14.3 \pm 1.5$ & $13.0 \pm 1.0$ & $8.7 \pm 1.2$ & $8.3 \pm 0.6$ \\
\hline $\mathrm{CU}$ & $17.0 \pm 1.0$ & $16.7 \pm 0.6^{* *}$ & $15.3 \pm 0.6^{* *}$ & $14.3 \pm 0.6^{* *}$ & $14.0 \pm 1.0$ & $13.7 \pm 0.6$ & $11.7 \pm 0.6$ & $10.3 \pm 0.6$ \\
\hline Amk & \multicolumn{4}{|c|}{24} & \multicolumn{4}{|c|}{21} \\
\hline
\end{tabular}

Numbers connote mean value \pm standard deviation $(n=3)$

${ }^{*} P<0.01,{ }^{* *} P<0.005$ 


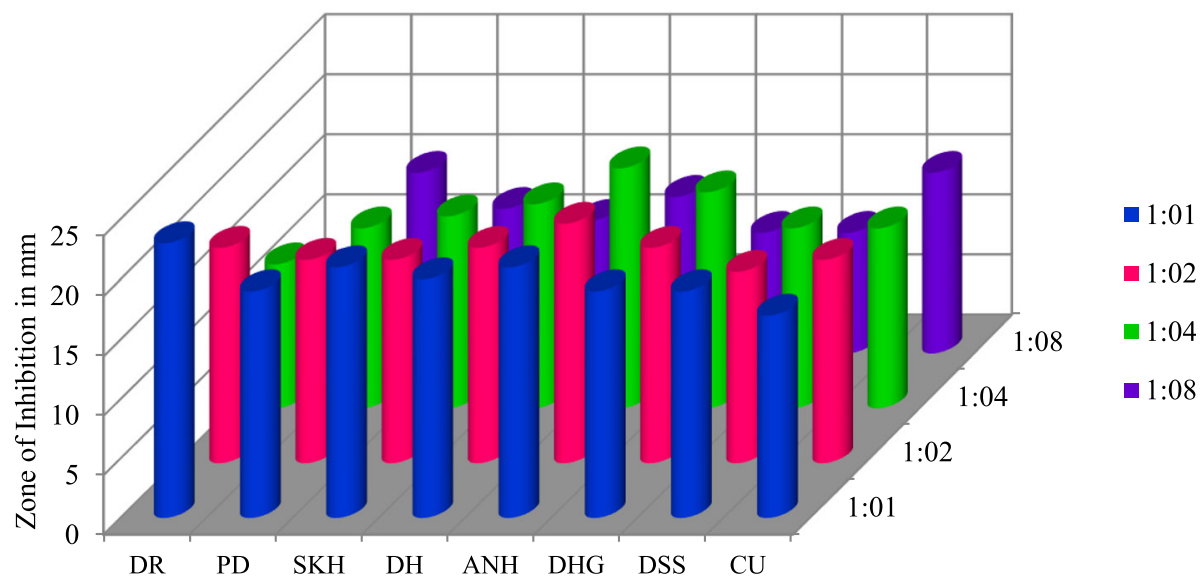

Fig. 2 Antibacterial sensitivity of S. aureus to different tested toothpastes

concentrations. The variation in conductivity of different toothpaste solutions at a certain concentration is likely due to the presence of many sizes and types of colloidal particles [17]. Toothpaste (DSS) has shown the highest specific conductivity. The higher the conductivity, the higher will be the charge in the pertaining ions and the higher will be the charge neutralized thereby increasing the cleansing behavior of the substances.

The positive slopes of the order DSS $>\mathrm{PD}>\mathrm{CU}>\mathrm{DR}$ $>$ DHG $>$ DH $>$ ANH $>$ SKH was found in the variations of specific conductivity with toothpaste concentration in distilled water at room temperature, whereas there was no reasonable trend in the intercept and almost negative values in the case of DR (Figure S3). The reason is that the very dilute composition of toothpaste in DW has a very low value of specific conductivity and therefore the cleansing action is low. Similarly, in tap water solutions, the positive slope indicates strong ion-ion interactions in the toothpaste solutions [33]. The high positive values of the intercepts indicate that the very dilute composition of toothpaste in tap water also has a relatively high value of specific conductivity and therefore the cleaning action is high [17].

Acidic toothpaste spoils the oral environment causing aciduric bacteria to cause dental caries. Research on the effects of $\mathrm{pH}$ on the enamel surface indicates enamel erosion from the dental surface due to low $\mathrm{pH}$ and high acid concentrations. The $\mathrm{pH}$ of 6.5 can initiate tooth demineralization and 5.5 can do enamel erosion [34]. Distilled water is often acidic and this nature is due to

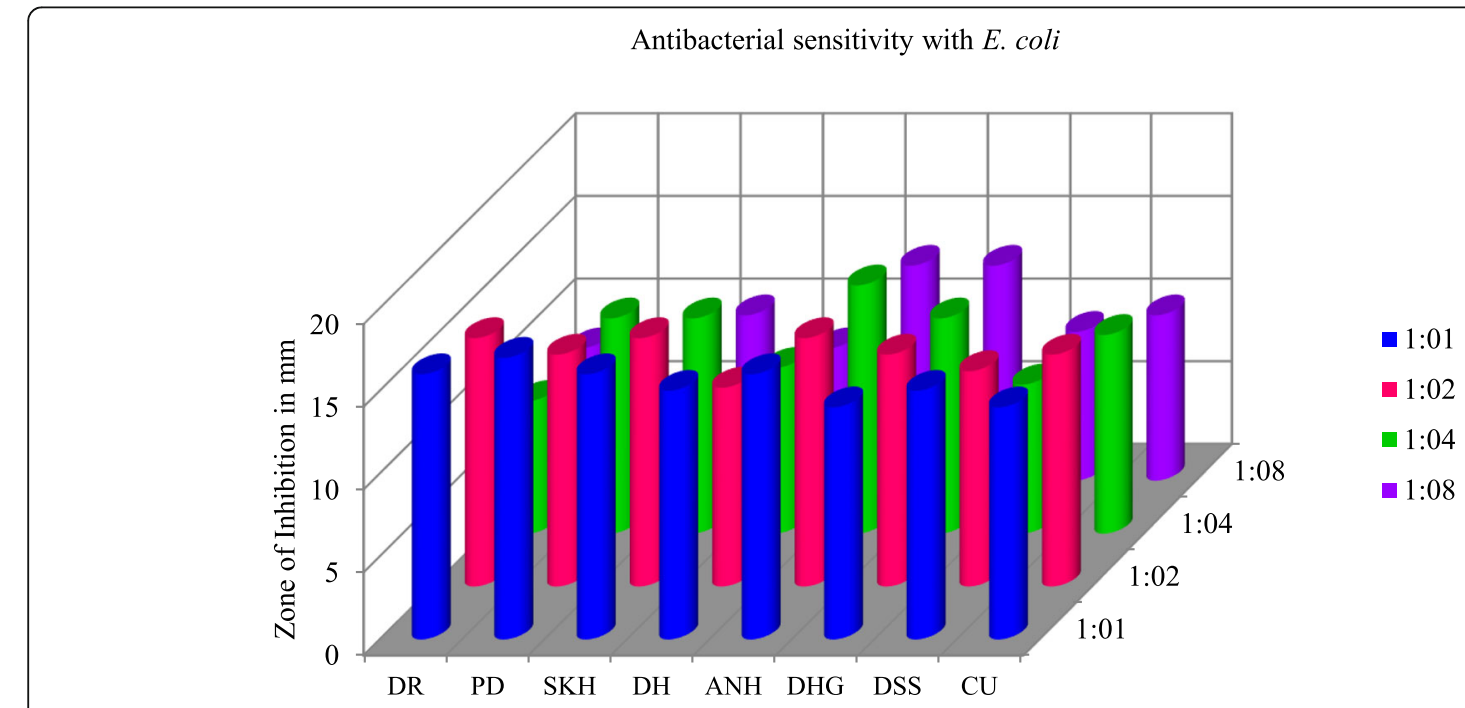

Fig. 3 Antibacterial sensitivity of $E$. coli to different tested toothpastes 
the dissolution of atmospheric $\mathrm{CO}_{2}$ which produces carbonic acid. Kulthanan et al. observed a pH of 5.7 for distilled water and 7.5 for water from home water filter which is similar to tap water [35]. So, in our study on eight types of toothpaste, dissolved in distilled water was found to have low $\mathrm{pH}$ while higher for tap water in all the investigated compositions.

Distilled water, as well as tap water, has the highest $\mathrm{pH}$ for DSS in all compositions while CU has the lowest $\mathrm{pH}$. The reason for the highest $\mathrm{pH}$ is due to the fact that DSS contains mostly alkaline ingredients (Table S1). The $\mathrm{pH}$ of calcium carbonate is around 9.91, and it is 8.35 for sodium bicarbonate regardless of the concentration. The reason for the lowest $\mathrm{pH}$ of $\mathrm{CU}$ is due to the presence of some acidic natural ingredients such as PEG-32 which has a pH of about 5 [36, 37]. The carbonated drinks can damage the tooth surface due to their low $\mathrm{pH}$ value. So it is recommended to use DSS, DR, PD, SKH, and DH toothpaste to remove acidic strains of the tooth surface [38].

$\mathrm{CaCO}_{3}$ as an abrasive in the toothpaste has a profound effect in forming alkaline medium and acts as a natural buffer in the oral environment while the others have a neutral effect. Baking soda as an abrasive has a beneficial role in neutralizing $\mathrm{pH}$ changes in acid-forming plaque after exposure to sucrose and in the caries inhibition $[39,40]$. Manufacturers formulate toothpaste to adjust $\mathrm{pH}$ value in the oral environment. The primary objective of toothpaste is to clean the approachable tooth surfaces with minimal damage to enamel, dentin, root surfaces, and gingival tissues due to mechanical abrasion of those surfaces. Relative abrasivity comparison of toothpaste is done by radioactive dentin abrasion (RDA) number [41, 42]. The lower the RDA number the lower will be the toothpaste's abrasion. One cannot assume that whitening toothpaste has high RDA numbers. Many whitening kinds of toothpaste are less abrasive than anti-tartar and smoker's toothpaste. Common ingredients of toothpaste include hydroxyapatite, xylitol, erythritol, and baking soda, which increase the $\mathrm{pH}$ in the mouth cavity.

The dietary acids from carbonated drinks and other beverage foods have higher potential for causing tooth erosion. The erosive effect is due to low $\mathrm{pH}$, low phosphate and high fluoride concentration, and also high buffering capacity $[43,44]$. On the other hand, a high $\mathrm{pH}$ value of the surrounding environment can cause irritation of pulp tissue and develop superficial necrosis on the exposed pulp and provoke mineralization on the necrotic zone [45]. It also creates a hostile environment for the proliferation and survival of the bacterial pathogen. Therefore, the detection of the $\mathrm{pH}$ value of toothpaste products is an important part of quality monitoring. And, we can ensure the stability of the toothpaste by controlling the $\mathrm{pH}$ in a reasonable range to control the dissociation rate. National and international toothpaste companies often pay more attention to this point, and they consider the $\mathrm{pH}$ value to be an important parameter to identify the quality of the toothpaste products [46]. Long exposure of the acidic environment gradually comes into contact with the dentine, the pain of which increases the gingival recession $[47,48]$. Also, root desorption and enamel demineralization have been reported at a $\mathrm{pH}$ of about 5.2 [38].

We have also reported the antibacterial sensitivity of toothpaste against two bacterial species, $S$. aureus and $E$. coli. While members of common flora of the oral cavity such as Streptococcus mutans, Streptococcus sobrinus, and some species of Lactobacillus are the usual causative agents of dental caries and gingivitis, several members of the "non-oral" microbiota inhabit the oral microenvironment due to ecological diversification in the oral cavity [49]. Besides, pathogenic "non-oral" bacteria such as $S$. aureus and $E$. coli are prevalent in subgingival biofilms of chronic periodontitis patients [50-52]. A high prevalence of periodontitis in non-smokers has also been associated with S. aureus [52]. Therefore, the roles of these bacteria as part of the etiology of caries and periodontal diseases cannot be ruled out. S. aureus is a nosocomial pathogen most commonly associated with hospital-acquired infections as well as communityacquired infections. This study focuses on testing the inhibitory effects of the toothpaste formulations on the common but "non-oral" pathogens that are associated with chronic dental infections. S. aureus and E. coli were chosen as the common representative species of Grampositive and Gram-negative groups, respectively. A future direction for the study may be to determine the antimicrobial effect of toothpaste formulations on specific "oral" pathogens associated with dental caries and periodontitis.

In this study, we investigated the active antimicrobial ingredients of toothpaste which can be formulated to reduce the deleterious effects of bacteria in oral flora. Most herbal-based toothpaste contains active antimicrobial ingredients to enhance antibacterial activity and is listed in Table S2. The addition of herbal extracts to toothpaste can enhance the antibacterial spectrum and can be enhanced by mixing with non-natural antibacterial agents [53]. Fluoride-containing toothpaste such as $\mathrm{SKH}, \mathrm{PD}, \mathrm{CU}$, and $\mathrm{ANH}$ enhance their effect on oral bacteria by direct inhibition of cellular enzymes and by easy permeation of hydrogen fluoride through cell membrane [54]. In general, the toothpaste showed similar patterns of inhibition with both $S$. aureus and E. coli bacteria in their variable compositional concentrations.

\section{Conclusion}

Oral biofilm formation is a common phenomenon in the oral environment that provokes bacterial growth and many kinds of oral diseases. The purpose of brushing 
the teeth using toothpaste is to remove oral biofilm and reduce bacterial attack. The chemical ingredients of toothpaste are the essential factors to measure their effectiveness in removing oral biofilms, and also to enhance their comparative quality. In addition to cleansing action, toothpaste acts to inhibit bacterial growth in the oral environment. In the present investigation, the study of solution properties detected increasing surface tension with decreasing concentration, decreasing conductivity with decreasing concentration, and slightly alkaline $\mathrm{pH}$ value of the investigated toothpaste. The weakly alkaline nature inhibits bacterial growth. The increasing surface tension and decreasing conductivity relative to decreasing concentration of toothpaste favor good cleansing activity. Moreover, bacterial inhibition further highlights the importance of toothpaste in public health research. All the investigated toothpaste formulations detected effective inhibition of growth of Gram-positive and Gramnegative bacteria and exhibited high inhibitory activities at concentrations of 1:1 and 1:2. Natural extracts added to toothpaste were found to further enhance the antibacterial spectrum. DR and PD showed greater inhibition effect against $S$. aureus and $E$. coli bacteria, respectively. Overall, the results suggest that the toothpaste formulations tested in this study are potentially effective in inhibiting bacteria that are associated with dental and gingival infections.

\section{Supplementary information}

Supplementary information accompanies this paper at https://doi.org/10. 1186/s43088-020-00050-2.

Additional file 1: Table S1 Ingredients of various toothpaste selected for antibacterial assessment. Table S2 Active antimicrobial ingredients of toothpastes. Figure $\mathbf{S 1}$ Surface tension Vs concentration of toothpaste samples in distilled water (DW) at room temperature. Figure S2 Surface tension Vs concentration of toothpaste samples in tap water (TW) at room temperature. Figure $\mathbf{S 3}$ Specific conductivity Vs concentration of toothpaste samples in distilled water (DW) at room temperature. Figure S4 Specific conductivity Vs concentration of toothpaste samples in Tap water (TW) at room temperature. Figure $\mathbf{S 5}$ Liner variations of specific conductivity Vs concentration of toothpaste samples in Distilled water at room temperature. Figure $\mathbf{S} 6$ Liner variations of specific conductivity Vs concentration of toothpaste samples in Tap water at room temperature. Figure $\mathbf{S 7} \mathrm{pH}$ Vs concentration of toothpaste samples in distilled water (DW) at room temperature. Figure $\mathbf{S 8} \mathrm{pH}$ Vs concentration of toothpaste samples in Tap water (TW) at room temperature.

\section{Abbreviations}

DR: Dabur Red; PD: Pepsodent; SKH: Srikhanda Herbal; DH: Dabur Herbal; ANH: Aagaman Neem Herbal; DHG: Dabur Herbal Gel; DSS: Dabur Super Salt; CU: Close Up; NB: Nutrient broth; NA: Nutrient agar; MHA: Mueller Hinton Agar; PEG: Polyethylene glycol; SMFP: Sodium Monoflourophosphate; RDA: Relative dentin abrasion; ATCC: American Type Culture Collection; DW: Distilled water; TW: Tap water

\section{Acknowledgements}

The authors are thankful to Prof. P. Mishra (Laboratory head) of Bio-inorganic and Materials Chemistry Research Laboratory and Surface Chemistry Research Laboratory of MMAMC for providing space for conducting this research. We are also grateful to the Department of Chemistry, MMAMC Biratnagar for providing necessary chemicals to pursue the research work.

\section{Authors' contributions}

NKC and BG performed the study and prepared manuscript. RLK managed antibacterial study and AB supervised the work. All authors have read and approved the manuscript.

\section{Funding}

This study has no funding.

Availability of data and materials

All the data generated and analyzed during the study are included in the manuscript and are available for the readers.

\section{Competing interest}

The authors declare that there are no competing interests regarding the publication of this paper.

Ethics approval and consent to participate

Not applicable

Consent for publication

Not applicable

\section{Author details}

${ }^{1}$ Department of Chemistry, Mahendra Morang Adarsh Multiple Campus, (Tribhuvan University), Biratnagar 56613, Nepal. ${ }^{2}$ Department of Biology, Saint Mary's College, Notre Dame, IN, USA.

Received: 28 December 2019 Accepted: 3 April 2020

Published online: 18 May 2020

\section{References}

1. Marsh PD (2004) Dental plaque as a microbial biofilm. Caries Res 38:204211. https://doi.org/10.1159/000077756

2. Zarco MF, Vess TJ, Ginsburg GS (2012) The oral microbiome in health and disease and the potential impact on personalized dental medicine. Oral Dis 18:109-120. https://doi.org/10.1111/j.1601-0825.2011.01851.x

3. Teles RP, Teles FRF (2009) Antimicrobial agents used in the control of periodontal biofilms: effective adjuncts to mechanical plaque control? Braz Oral Res. https://doi.org/10.1590/\$1806-83242009000500007

4. Smith AJ, Robertson D, Tang MK, Jackson MS, MacKenzie D, Bagg J (2003) Staphylococcus aureus in the oral cavity: a three-year retrospective analysis of clinical laboratory data. Br Dent J 195:701-703. https://doi.org/10.1038/sj. bdj.4810832

5. McCormack MG, Smith AJ, Akram AN, Jackson M, Robertson D, Edwards G (2015) Staphylococcus aureus and the oral cavity: an overlooked source of carriage and infection? Am J Infect Control 43:35-37. https://doi.org/10. 1016/j.ajic.2014.09.015

6. Padhiary SK, Srivastava G, Panda S, Subudhi S, Lenka S (2013) E.coli associated extensive bilateral maxillary osteomyelitis: a rare case report. J Clin Diagnostic Res 7:2380-2382. https://doi.org/10.7860/JCDR/2013/5628.3531

7. Sbordone L, Bortolaia C (2003) Oral microbial biofilms and plaque-related diseases: microbial communities and their role in the shift from oral health to disease. Clin Oral Investig 7:181-188. https://doi.org/10.1007/s00784-003-0236-1

8. Park S-C, Park Y, Hahm K-S (2011) The role of antimicrobial peptides in preventing multidrug-resistant bacterial infections and biofilm formation. Int J Mol Sci 12:5971-5992. https://doi.org/10.3390/ijms12095971

9. Verkaik MJ, Busscher HJ, Jager D, Slomp AM, Abbas F, Van Der Mei HC (2011) Efficacy of natural antimicrobials in toothpaste formulations against oral biofilms in vitro. J Dent 39:218-224. https://doi.org/10.1016/j.jdent.2010. 12.007

10. Kiani M, Firoozian F, Moradkhani S (2017) Formulation and physicochemical evaluation of toothpaste formulated with Thymus vulgaris essential oil. $J$ HerbMed Pharmacol 6:130-135

11. Majeti S, Bapat NV, Clymer PD, Reno EA, Glandorf WM, Kovacs SA (2004) Oral compositions providing enhanced overall cleaning, $\mathrm{p} 2$

12. Vranic E, Lacevic A, Mehmedagic A, Uzunovic A (2004) Formulation ingredients for toothpastes and mouthwashes. Bosn J Basic Med Sci 4: $51-58$ 
13. Davies RM, Ellwood RP, Davies GM (2003) The rational use of fluoride toothpaste. Int J Dent Hyg:3-8. https://doi.org/10.1034/j.1601-5037.2003. $00001 . x$

14. Radafshar G, Mahbooob F, Kazemnejad E (2010) A study to assess the plaque inhibitory action of herbal-based toothpaste : a double blind controlled clinical trial. J Med Plants Res 4:1182-1186. https://doi.org/10.5897/JMPR10. 051

15. Anushree B, Fawaz MA, Narahari R, Shahela T, Syed A (2015) Comparison of antimicrobial efficacy of triclosan-containing, herbal and homeopathy toothpastes- an in vitro study. J Clin diagnostic Res 9:DC05-DC08. https:// doi.org/10.7860/JCDR/2015/11984.6626

16. Omar KA, Ismail AK, Amin CM, Jalal MS, Qadr SN, Rafiq ZF (2017) Physicochemical characteristics of toothpastes and natural powder and their antibacterial activity against Viridans Streptococci bacteria. Orient J Chem 33:2566-2572. https://doi.org/10.13005/ojc/330553

17. Hattiangdi GS, Walton WW, Hoffman JI (1949) Some physical chemical properties of aqueous solutions of soaps and soapless detergents. Natl Bur Stand 42:361-368

18. Niraula TP, Chatterjee SK, Bhattarai A (2018) Micellization of sodium dodecyl sulphate in presence and absence of alkali metal halides at different temperatures in water and methanol-water mixtures. J Mol Liq. https://doi. org/10.1016/j.molliq.2017.12.014

19. Van Asselt AJ, Van Houwelingen G, Te Giffel MC (2002) Monitoring system for improving cleaning efficiency of cleaning-in-place processes in dairy environments. Trans Inst Chem Eng Part C 80:276-280. https://doi.org/10. 1205/096030802321154772

20. Hilgenberg SP, Pinto SCS, Farago PV, Santos FA, Wambier DS (2011) Physical-chemical characteristics of whitening toothpaste and evaluation of its effects on enamel roughness. Braz Oral Res 25:288-294. https://doi.org/ 10.1590/S1806-83242011005000012

21. Kielbassa AM, Gillmann L, Zantner C, Meyer-Lueckel H, Hellwig E, SchulteMönting J (2005) Profilometric and microradiographic studies on the effects of toothpaste and acidic gel abrasivity on sound and demineralized bovine dental enamel. Caries Res 39:380-386. https://doi.org/10.1159/000086844

22. Okpalugo J, Ibrahim K, Inyang US (2009) Toothpaste formulation efficacy in reducing oral flora. Trop J Pharm Res 8:71-77. https://doi.org/10.4314/tjpr. v8i1.14714

23. Holder IA, Boyce ST (1994) Agar well diffusion assay testing of bacterial susceptibility to various antimicrobials in concentrations non-toxic for human cells in culture. Burns 20:426-429. https://doi.org/10.1016/03054179(94)90035-3

24. Balouiri M, Sadiki M, Ibnsouda SK (2016) Methods for in vitro evaluating antimicrobial activity: a review. J Pharm Anal 6:71-79. https://doi.org/10. 1016/j.jpha.2015.11.005

25. Valgas C, Machado de Souza S, Smânia EF, Smânia A Jr (2007) Screening methods to determine antibacterial activity of natural products. Brazilian J Microbiol 38:369-380. https://doi.org/10.1590/S1517-83822007000200034

26. Chaudhary NK, Mishra P (2018) Bioactivity of some divalent M(II) complexes of penicillin based Schiff base ligand: synthesis, spectroscopic characterization, and thermal study. J Saudi Chem Soc 22:601-613. https:// doi.org/10.1016/j.jscs.2017.10.003

27. Chaudhary NK, Mishra P (2017) Metal complexes of a novel Schiff base based on penicillin: characterization, molecular modeling, and antibacterial activity study. Bioinorg Chem Appl. doi: 10.1155/2017/6927675. doi: https:// doi.org/10.1155/2017/6927675

28. Woloj M, Tolmaksy ME, Roberts MC, Crosa JH (1986) Plasmid-encoded amikacin resistance in multiresistant strains of Klebsiella pneumoniae isolated from neonates with meningitis. Antimicrob Agents Chemother 29: 315-319. https://doi.org/10.1128/AAC.29.2.315

29. Ramirez MS, Tolmasky ME (2017) Amikacin: uses, resistance, and prospects for inhibition. Molecules. https://doi.org/10.3390/molecules22122267

30. Vatanparast H, Shahabi F, Bahramian A, Javadi A, Miller R (2018) The role of electrostatic repulsion on increasing surface activity of anionic surfactants in the presence of hydrophilic silica nanoparticles. Sci Rep 8:1-11. http://dx. doi.org/https://doi.org/10.1038/s41598-018-25493-7

31. Gordon SM, Shand EW (1932) Surface tension of tooth paste solutions. Ind Eng Chem 24:1148-1152. https://doi.org/10.1021/ie50274a014

32. Barkvoll P (1989) Should toothpastes foam? Sodium lauryl sulfate--a toothpaste detergent in focus. Den Nor Tann 99:82-84

33. Bhattarai A, Nandi P, Das B (2006) The effects of concentration, relative permittivity and temperature on the transport properties of sodium polystyrenesulphonate in methanol-water mixed solvent media. J Polym Res 13:475-482. https://doi.org/10.1007/s10965-006-9070-x

34. Sahlan M, Purwanti L (2017) Tooth spray with active ingredients casein phosphopeptide - amorphous calcium phosphate (CPP-ACP) and ethanolic extract propolis (EEP) to inhibit tooth demineralization. Commun Sci Technol 1:56-60

35. Kulthanan K, Nuchkull P, Varothai S (2013) The pH of water from various sources: an overview for recommendation for patients with atopic dermatitis. Asia Pac Allergy 3:155. https://doi.org/10.5415/apallergy.2013.3.3.155

36. Jurnak $F$ (1986) Effect of chemical impurities in polyethylene glycol on macromolecular crystallization. J Cryst Growth 76:577-582. https://doi.org/ 10.1016/0022-0248(86)90174-0

37. Ray WJ, Puvathingal JM (1985) A simple procedure for removing contaminating aldehydes and peroxides from aqueous solutions of polyethylene glycols and of nonionic detergents that are based on the polyoxyethylene linkage. Anal Biochem 146:307-312. https://doi.org/10. 1016/0003-2697(85)90544-5

38. Price RBT, Sedarousy M, Hiltz GS (2000) The pH of tooth-whitening products. J Can Dent Assoc (Tor) 66:421-426

39. Dawes $\mathrm{C}$ (2003) What is the critical pH and why does a tooth dissolve in acid? J Can Dent Assoc 69:722-724. https://doi.org/10.1016/S10723498(37)80084-9

40. Tanzer JM, McMahon T, Grant L (1990) Bicarbonate-based powder and paste dentifrice effects on caries. Clin Prev Dent

41. Hefferren JJ, Kingman A, Stookey GK, Lehnhoff R, Muller T (1984) An international collaborative study of laboratory methods for assessing abrasivity to dentin. J Dent Res 63:1176-1179

42. Hefferren JJ (1976) A laboratory method for assessment of dentrifrice abrasivity. J Dent Res 55:563-573

43. Ireland AJ, McGuiness N, Sherriff M (1995) An investigation into the ability of soft drinks to adhere to enamel. Caries res 29:470-476. doi: 10.15713/ins.mmj.3

44. Lussi A, Jaggi T, Scharer S (1993) The influence of different factors on in vitro enamel erosion. Caries Res 27:387-393. doi: 10.15713/ins.mmj.3

45. Poggio C, Lombardini M, Colombo M, Beltrami R, Rindi S (2015) Solubility and $\mathrm{pH}$ of direct pulp capping materials: a comparative study. J Appl Biomater Funct Mater 13:e181-e185. https://doi.org/10.5301/jabfm.5000230

46. Ni YN, Lin W (2011) Near-infrared spectra combined with partial least squares for $\mathrm{pH}$ determination of toothpaste of different brands. Chinese Chem Lett 22:1473-1476. http://dx.doi.org/https://doi.org/10.1016/j.cclet. 2011.07.010

47. Arnold WH, Haase A, Hacklaender J, Gintner Z, Bánóczy J, Gaengler P (2007) Effect of $\mathrm{pH}$ of amine fluoride containing toothpastes on enamel remineralization in vitro. BMC Oral Health 7:3-7. https://doi.org/10.1186/ 1472-6831-7-14

48. Addy M (2005) Tooth brushing, tooth wear and dentine hypersensitivity are they associated? Int Dent J 55:261-267. https://doi.org/10.1111/j.1875595X.2005.tb00063.X

49. Vieira Colombo AP, Magalhães CB, Hartenbach FARR, Martins do Souto R, Maciel da Silva-Boghossian C (2015) Periodontal-disease-associated biofilm: a reservoir for pathogens of medical importance. Microb Pathog 94:27-34. https://doi.org/10.1016/j.micpath.2015.09.009

50. Loberto JCS, Martins CAP, dos Santos SSF, Cortelli JR, Jorge AOC (2004) Staphylococcus Spp. in the oral cavity and periodontal pockets of chronic periodontitis patients. Brazilian J Microbiol 35:64-68. https://doi.org/10.1590/ S1517-83822004000100010

51. Souto R, de Andrade AFB, Uzeda M, Colombo APV (2006) Prevalence of non-oral pathogenic bacteria in subgingival biofilm of subjects with chronic periodontitis. Brazilian J Microbiol 37:208-215. https://doi.org/10.1590/ S1517-83822006000300002

52. Zinsli Fritschi B, Albert-Kiszely A, Persson GR (2008) Staphylococcus aureus and other bacteria in untreated periodontitis. J Dent Res 87:589-593. https://doi.org/10.1177/154405910808700605

53. De Rossi A, Ferreira DCA, da Silva RAB, de Queiroz AM, da Silva LAB, NelsonFilho P (2014) Antimicrobial activity of toothpastes containing natural extracts, chlorhexidine or triclosan. Braz Dent J 25:186-190

54. Buzalaf MAR, Pessan JP, Honório HM, ten Cate JM (2011) Mechanisms of action of fluoride for caries control. Monogr Oral Sci 22:97-114

\section{Publisher's Note}

Springer Nature remains neutral with regard to jurisdictional claims in published maps and institutional affiliations. 